\title{
Using Fuzzy Time Series (FTS) and Linear Programming for Production Planning and Planting Pattern Scheduling Red Onion
}

\author{
Aries Dwi Indriyanti ${ }^{1, *}$, Dedy Rahman Prehanto ${ }^{1}$, Ginanjar Setyo Permadi ${ }^{3}$, Chamdan Mashuri ${ }^{2}$, and Tanhella Zein \\ Vitadiar $^{2}$ \\ ${ }^{1}$ Informatics Engineering Department, of Engineering Faculty, Surabaya State University, Surabya- Indonesia \\ ${ }^{2}$ Information System Department of Information Technology Faculty, Hasyim Asy'ari University, Jombang - Indonesia \\ ${ }^{3}$ Informatics Management Department of Information Technology Faculty, Hasyim Asy'ari University, Jombang - Indonesia
}

\begin{abstract}
This study discusses the production planning system and scheduling shallots planting patterns using fuzzy time series and linear programming methods. In this study fuzzy time series to predict the number of requests and the results of predictions from fuzzy time series methods become one of the variables in the calculation of linear programming. Using supporting variables, demand data, production data, employment data, land area data, production profit data, data on the number of seedlings and planting time data are indicators used in processing the system. The system provides recommendations for cropping patterns and the number of seeds that must be planted in one period. The age of harvesting onions is $\pm 3-4$ months from the planting process, the number of planting seeds is adjusted to the number of requests that have been predicted by using fuzzy time series and cropping pattern calculation process is carried out using linear programming. The results of this system are recommendations for farmers to plant seedlings, planting schedules, and harvest schedules to meet market demand.
\end{abstract}

Keywords: Production planning; cropping pattern; Fuzzy Time Series; linear programming.

\section{Introduction}

Planning is an important problem for researchers, academic actors, and industry players because planning is the first step to start an activity. Also in the industrial world, planning is needed to produce goods. With the planning of the production of goods, the productivity of the company can be increased [1]. There are several factors that influence the planning of production, including the level of consumer demand, the amount of profit to be achieved, the cost of production, the level of fulfillment of resources that include natural resources and human resources, and procedures for rescheduling production. In the case of agriculture, planning is needed to reschedule the planting period, so that it can be predicted that the harvest period and farmer productivity will increase [2].

A farmer in making a planting schedule must pay attention to the influential attributes so that abundant yields are obtained with high profits for the farmers. The attributes that influence it include, number of seeds, area, production excellence, planting time (plant age), and length of the production process. This study took a case study of horticultural plants, namely onion, with a planting period of up to 100-120 days, depending on the type of red variety.
In an effort to improve crop yields, good and appropriate planning and scheduling are needed, therefore a calculation model is needed that is able to overcome these problems. The calculation model that can be applied is a linear programming model because this model is able to provide several alternatives that support the right decision making, so as to optimize the results to be achieved [3].

The process of drawing decisions for farmers will be helped by the application of linear programming by adjusting the conditions of the farmers, with various alternatives in the planning and scheduling process to achieve the main objectives with limited resources. These problems and limitations are often found in farmers, such as limited land area, lack of manpower or human resources, lack of costs, and limited agricultural equipment that is not feasible, so that the implementation of linear programming is expected to help farmers to maximize crop yields, and productivity despite limitations [4].

The linear programming model is composed of two kinds of coefficients, namely the objective function and the constraint function, where the objective function means to describe the mathematical equations of the objectives obtained, while the constraint function is used to describe the mathematical equations in the effect of production [5]. After writing the mathematical equation,

\footnotetext{
* Corresponding author: aries.dwi11@yahoo.com
} 
the next step is to calculate the simplex method. In linear programming there is also sensitivity analysis, this is because the results of calculations can occur uncertainty, with sensitivity to apply the resource parameters that exist in part of the lower limit and the upper limit, it is permissible to change parameters to a certain extent [6].

The initial stage in developing cropping patterns begins with knowing the data requirements because data requirements are the initial key to starting the next process. Data in the field shows that consumer satisfaction is very influential on business continuity, therefore it must be able to meet every consumer demand. When the relationship between the consumer and the producer is well established, the profit will increase. In addressing each customer's different requests and the existence of excesses and shortages of stock, for that purpose predictions will be applied by using fuzzy time series forecasting to predict the amount of consumer demand in the future, based on demand data in the past. The concept of fuzzy calculations is based on fuzzy set theory, fuzzy logic, and estimates [7].

Previous studies have been conducted by Rocco and Morabito, who conducted research on production planning scheduling on tomato horticultural plants [1], and on citrus plants by Munhoz and Morabito [8], different from the research in this paper which took on case studies of onion horticulture plants red using two methods namely linear programming and fuzzy time series.

Production planning is one of the important activities carried out by a company because with good production planning it will be able to control the production process so that there is no excess product or lack of products but in accordance with consumer demand. This information scheduling and planning system is expected to be able to help companies and farmers meet market and consumer demand effectively and efficiently so that consumers will be satisfied and the company's profits can be maximally achieved.

\section{Theoretical framework}

\subsection{Production planning}

The production is a set of procedures or activities conducted to create goods and services, in any production process required a planning process. Production planning is planning about what products and how they will be produced by the company in question in a period to come. Production planning is part of operational planning within the company. In the preparation of production planning, things to consider are the optimization of production so as to be able to achieve the lowest cost level for the implementation of the production process [9]. The role of planning is merely intended to coordinate the activities of the sections that directly or indirectly in producing, planning, scheduling and controlling the production of the starting stages of raw materials, process, until the resulting output so that the company really can produce goods or services effectively and efficiently.
Some of the goals of production planning, namely as a preliminary step to determine the activity of production, as a reference to more detailed planning, the input of resource plans resource planning so that it can be developed to support production planning, production and labor stability against fluctuations in demand.

\subsection{Scheduling of planting pattern}

The cropping pattern of scheduling is plantings on a plot of land with a set order of the layout and sequence of the plant over a given period includes the period of tillage and the period didn't plant during a certain time period [10]. Plants in one area can be set according to its kind. Monoculture cropping pattern exists, namely the growth of plants similar to the one planting acreage. There is a mixed cropping pattern, i.e., plants are grown in a single area. There is also a growing pattern of passes, that is, planting crops, in turn, some kinds of plants at different times on the same acreage.

In planning the production agribusiness factor to note is the cropping pattern so that scheduling can increase the profits of agriculture [11]. In the preparation of the scheduling is expected to reduce the delays in the work, and the processing time, maximizing the available working tools and labor as well as reduce the time delay

\subsection{Information system}

Information system is a tool to present information so beneficial to the recipient for decision making on planning, controlling, and organizational management of the company, information systems are used to automate the performance of routine and management activities [12]. The field of information technology is very special because always follow the dynamic changes that develop every year there is always a new version in terms of hardware and software [13]. The basic concepts of information. The information system is expected to simplify and automate all the performance in the field of any kind of health, education, and agriculture.

\subsection{Fuzzy time series}

Fuzzy time series a concept based on fuzzy set theory and its linguistic connection and application variables, fuzzy time series are used to solve the problem of forecasting which historical data are linguistic values. For example, in the matter of forecasting, historical data is not in the form of real numbers, but in the form of linguistic data. In this case, there is no conventional time series model that can be applied, but the fuzzy time series models can be applied with more precision. The main difference between the conventional and the fuzzy time series is in the value used in forecasting, which is a fuzzy set of the real numbers over the set of hosts is specified, fuzzy set is defined as a class of numbers with vague boundaries, in this paper, fuzzy time series applied to the sale of horticulture crops in this study is mushroom, fuzzy time series used to predict demand of 
next month, the parameter used are January 2014 until April 2019.

Steps by steps with the prediction method of Fuzzy Time Series [14].

1. Partition the universe of discourse $U=[$ Drnin - D1, Dmax -[- D2] into even lengthy and equal length intervals $\mathrm{ul}, \mathrm{u} 2, \ldots, \mathrm{um}$, historical sales of red onion data January 2014 - April 2019. (1)

2. Let $\mathrm{A} 1, \mathrm{~A} 2, \ldots, \mathrm{A} \mathrm{k}$ be fuzzy sets which are linguistic values of the linguistic variable "enrollments". Define fuzzy sets A1, A2, .., Ak on the universe of discourse U. (2)

3. Divide the derived fuzzy logical relationships into groups based on the current states of the enrollments of fuzzy logical relationships, by using the formula:

$$
\mathrm{r}(\mathrm{MBF})_{\mathrm{w}+1}=\frac{\mathrm{MBF}_{1}+\mathrm{MBF}_{2}+\ldots+\mathrm{MBF}_{\mathrm{w}}}{\mathrm{W}}
$$

Where MBF1, MBF2, MBFw is the membership value of the sales historical data.

4. Calculate the forecasted outputs use the Center of Grafity method (COG). By using the formula:

$$
\begin{array}{ll}
y=\frac{\left(\mathrm{A} 1 * \mathrm{cl}+\mathrm{A} 2 * \mathrm{c} 2+\mathrm{A} 33^{*} \mathrm{c} 3+\ldots+\mathrm{A} 7 * \mathrm{c} 7\right)}{\mathrm{A} 1+\mathrm{A} 2+\mathrm{A} 3+\ldots+\mathrm{A} 7} \\
\mathrm{r}(\mathrm{NS}) * \mathrm{Al}+\mathrm{r}(\mathrm{NM}) * \mathrm{~A} 2+\ldots+\mathrm{r}(\mathrm{PB}) * \\
\mathrm{v}=\mathrm{A} 7 \\
\mathrm{Fi}=\mathrm{y}+\mathrm{v}
\end{array}
$$

\subsection{Linear programming}

Linear Programming is a general model that can be used to solving the problem of allocating limited resources optimally. The linear program includes planning activities to attain optimal results that is an outcome which reflects the achievement of a specific target is the best (according to a mathematical model) between the alternatives are possible by using a linear function, with the extant problems i.e. optimize a linear functions are limited by constraints in the form of the equation and a linear inequality [13].

In Linear Programming, there are two kinds of linear functions as follows:

a. The destination function (objective function) is a function that leads analysts to detect goal formulation problems.

b. The function of the constraints that is a direct function of the analyst to know the resources available and the demand for these resources

Linear programming right used to potentially problematic agriculture horticulture because agricultural resources horticulture limited, a case study the research is plant of a mushroom where linear programming used to optimize advantage existing with problems such as demand was, the production not been able to meet the demand that is, the workforce in need, their land less optimized, several variables need in optimize advantage is the data on demand, data production, the number of labor, data their land, data advantage production, the number of seeds and old data grow and inserted into the equation linear. A common form of linear programming: Maximize:

a) Objective Function: $Z=c 1 \times 1+c 2 \times 2+\ldots+$ cnxn (6)

b) Constraint: (7)

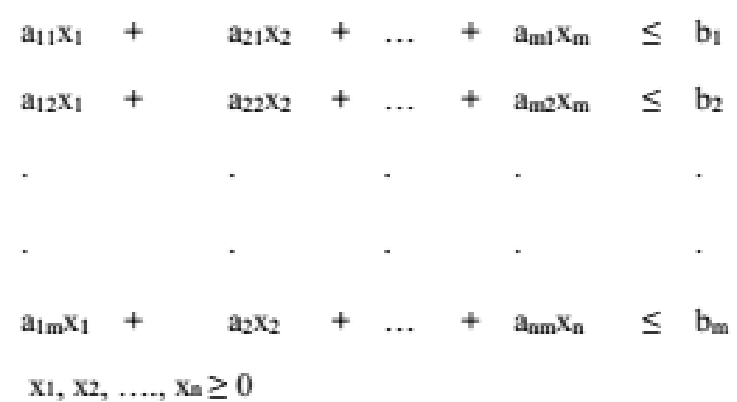

Based on a common form of linear programming, so can be concluded:

1. This is linear programming there must be function purpose (expressed with the equation a straight line function $\mathrm{z}$ or $\mathrm{f}(\mathrm{z})$ ) namely benefit sales by must be agriculture.

2. Linear programming must constraints expressed with the equation a straight line, the input in function obstacles in the agricultural sector that affects sales have to less than equal to available resources on the farm.

3. Is that all value $\mathrm{x}$ is positively or equals 0 . Or in other words, there is no negative value of $\mathrm{x}$. Thus hence the magnitude of the coefficients input-output should not be negative.

The next phase is a method of settlement with simplex. It is a method of procedure simplex algebra that is spatially the iterative moving step by step toward the point of optimal, formulations of a method of simplex [13]. $x_{1}, x_{2}, \ldots, x_{n} \geq 0$ is :

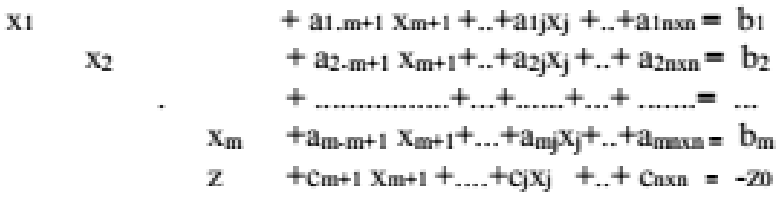

In a method of simplex function problem with inequality $((\leq)$ to be turned into equation $(=), \mathrm{z}$ is the variable the base while alj, cj, b1 and z0 is the constant .To solution get a optimal then $x n$ to be zero, in the form of canonical solution essentially as follows

$\mathrm{z}=\mathrm{z} 0, \mathrm{x} 1=\mathrm{b} 1, \mathrm{x} 2=\mathrm{b} 2, \ldots, \mathrm{xm}=\mathrm{bm}, \mathrm{xm}+1=\mathrm{xm}+2, \ldots$. $=\mathrm{xn}=0$

In assigning value to optimal there should not be a negative value if there is to be multiplied by $(-1)$ so that the $b 1, b 2, \ldots, b m \geq 0$

\section{Methodologies}

This information system framework focuses on data processing, where at the input stage there are sales data, production data, labor force data, land area data, production profit data, seed number data, and planting area data. Input from sales data will go into the process section that will be predicted by consumer demand using the fuzzy time series method, then the results will be stored in the local database. While the input from production data, labor force data, land area data, production profit data, seed number data, and planting area data are stored in the database. From the data in the database, a mathematical formulation will be made using a linear programming model to determine the objective 
function and constraint function. Where the objective function is useful to increase profits and constraint functions to minimize the obstacles that occur. The constraint function consists of labor constraints, land area, and demand. The next step is to solve the optimization problem with the simplex method, it will get the output of determining the schedule of cropping patterns (planting time and harvest time) in the form of a table of cropping pattern schedules and the number of seeds that must be planted in one period. The results of fuzzy time series analysis and linear programming will consider in determining the planting schedule and harvest schedule as well as the number of seeds that must be planted in one period so that it can increase profits in Fig 1.

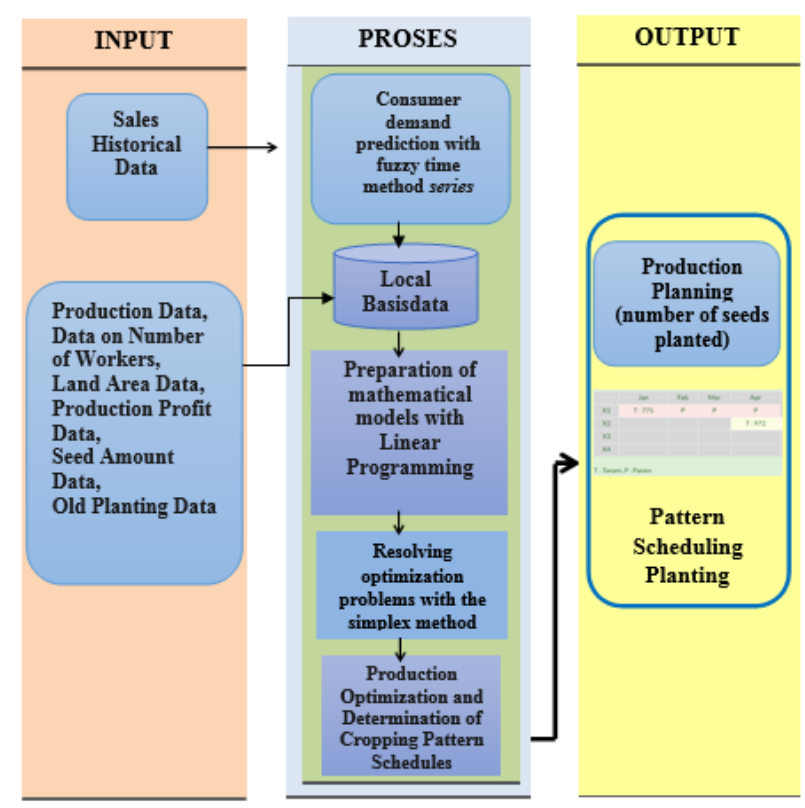

Fig. 1. Information system framework

\section{Result and Discussion}

The result of this research provides display system information on planning the production and scheduling planting patterns by applying a method of programming linear and fuzzy time series values is the selling data January 2012 - April 2017, so that obtained the results of optimizing the production and scheduling of planting patterns. The results of data processing fuzzy time series of the results of a prediction demand for months later will be used as a function obstacles in the process of programming linear, by making formulation mathematics the determination of function the purpose and obstacles based on variables for which there are in order to obtain optimize the production and scheduling planting patterns to optimize advantage production with planted the seed mushroom in accordance with a demand months later so mushroom produced according to demand that is.

Initial phase data processing started by noting the selling data, production, profit production, long planting, the amount of labor and there have in the agricultural sector mushroom the selling data January 2014 - April
2019 mixed with fuzzy time series to produce data demand for months later. Data demand, history of planting, the amount of labor and there have will be variable function obstacles data on advantage production will be functions of the purpose of which will be formulated in the form of mathematics by using programming linear, of the results of data processing will get some of the scenarios with the lapse of time planting mushroom different, the lapse of time planting start of an interval planting one month to hose planting 4 months to produce sum advantage different also from here function of incorporation fuzzy time series and linear programming namely optimize advantage farmers a mushroom with planting seeds mushroom in accordance with an estimated demand months later so can produce red onion in accordance with consumer demand.

The planning process of producing and scheduling the planting patterns commenced by determining prediction demand months later using data historical sales a few years back, the data used was the selling data from year January 2012 - April 2017, the process prediction demand by using the method fuzzy time series.

Steps in the fuzzy time series are:

1. Partition the universe of discourse $U=[$ Drnin - D1, Dmax -[- D2] into even lengthy and equal length intervals ul, u2, ..., um (1). Based on data of year January 2012 - April 2017, obtained a universe of discourse as follows:

Dmin $=133$ dan Dmax $=598$, Divided long intervals as many as 7 so obtained $\mathrm{u} 1-\mathrm{u} 7$ such as Table 1 .

Table 1. Number of interval

\begin{tabular}{|l|r|r|r|}
\hline uI & 133 & 199.4286 & 1 \\
\hline u2 & 199.4285714 & 265.8571 & 3 \\
\hline u3 & 265.8571429 & 332.2857 & 9 \\
\hline u4 & 332.2857143 & 398.7143 & 9 \\
\hline u5 & 398.7142857 & 465.1429 & 20 \\
\hline u6 & 465.1428571 & 531.5714 & 8 \\
\hline u7 & 531.5714286 & 598 & 12 \\
\hline
\end{tabular}

2. Defines the set of fuzzy in of $U$ with determine the value of $\mathrm{nb}$ (negative big), nm (negative medium), ns (negative small), z (zero), ps (positive small), pm (positive medium) and $\mathrm{pb}$ (positive big) a curve to describe variation from the sale, as in a picture 2.( 2 )

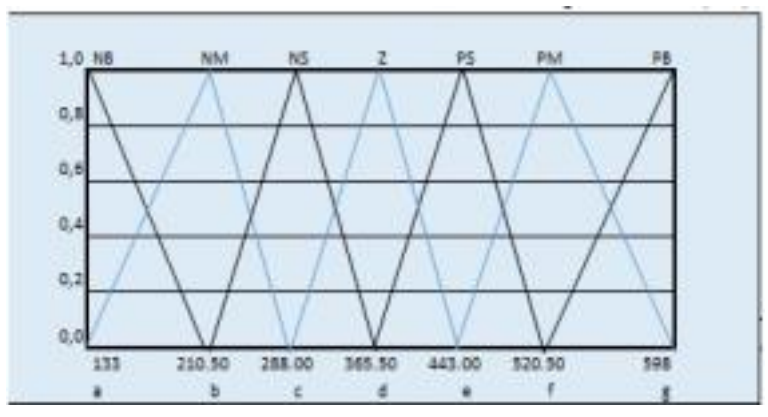

Fig. 2. Universe of discourse 
3. Fuzzification historical data with the $\mathrm{w}=1$, in Fig. 3 explained the process fuzzification the final period. Namely January 2014 - April 2017. (3)

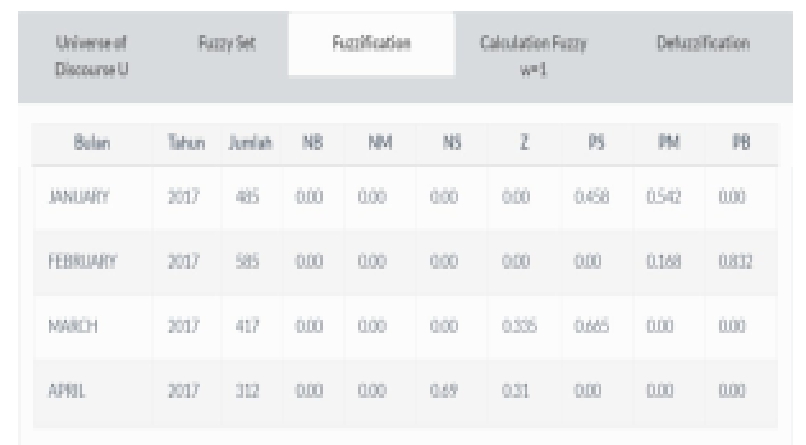

Fig. 3 Fuzzification process

4. Defuzzification, in Fig. 4 explained the result of a prediction in the final period to be used as variable demand at calculation linear programming and value MAPE.(4)

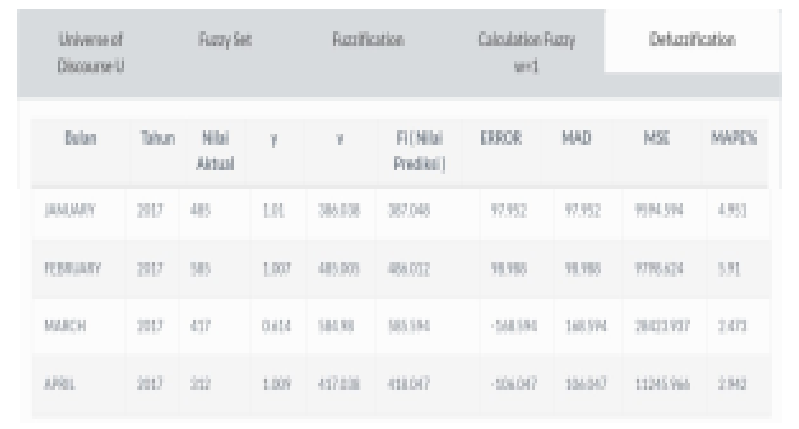

Fig. 4. Table the results of a prediction fuzzy

After obtained the results of predictive value demand may as many as 418 , so predictive value is used as variable consumer demand in function obstacles in calculation linear programming. Besides variable consumer demand that to be functions of obstacles is variable amount of sales, there have, working hours and the amount of labor (the coefficients) and variable advantage production to be functions of the purpose.

Besides the determination of function the purpose and obstacles are scenarios optimize consisting of scenario one, two and three where scenario one distance planting mushrooms in one batch have hose planting one month, scenario two have hose planting two months and scenario of 3 have hose planting 3 months and scenario 4 have hose planting four months.

Calculation resolved with the methods simplex who has formulated in the form of mathematical linear model programming. The data required for the planning the producing and scheduling of planting patterns are presented in Fig, 5.

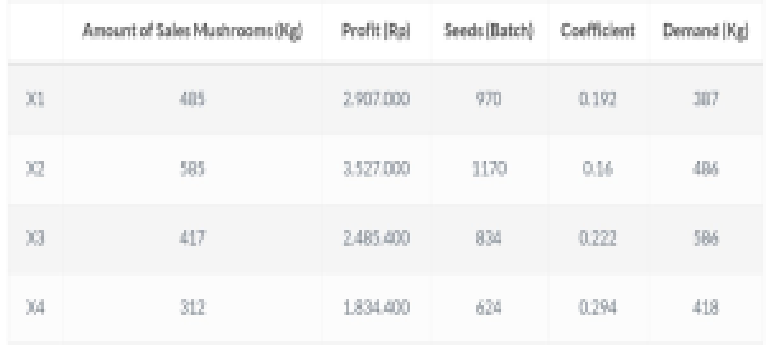

Fig. 5. Data for a period

The next step is to formulating into mathematical form linear programming.

1. Formulation programming of linear programming scenario 1

Objective Fuction

$\mathrm{Z}=2907000 \mathrm{X} 1+3527000 \mathrm{X} 2+2485000 \mathrm{X} 3+$ $1834000 \mathrm{X} 4$

(profit) (6)

Constraints (7)

$0.19 \mathrm{X} 1+0.16 \mathrm{X} 2+0.22 \mathrm{X} 3+0.29 \mathrm{X} 4<=288$

(koefisien)

$970 \mathrm{X} 1+1170 \mathrm{X} 2+834 \mathrm{X} 3+624 \mathrm{X} 4<=5000$

$485 \times 1<=387$

$1070 \times 2<=486$

$1487 \times 3<=586$

$1314 \times 4<=418$

2. Formulation programming of linear programming scenario 2

Objective Fuction

$\mathrm{Z}=2907000 \mathrm{X} 1+3527000 \mathrm{X} 2+2485000 \mathrm{X} 3+$ $1834000 X 4$

(profit) (6)

Constraints (7)

$0.19 \mathrm{X} 1+0.16 \mathrm{X} 2+0.22 \mathrm{X} 3+0.29 \mathrm{X} 4<=288$

(koefisien)

$970 \mathrm{X} 1+1170 \mathrm{X} 2+834 \mathrm{X} 3+624 \mathrm{X} 4<=5000$

$485 \times 1<=387$

$1070 \times 2<=486$

$1002 \times 3<=586$

$729 \times 4<=418$

3. Formulation programming of linear programming scenario 3

Objective Fuction

$\mathrm{Z}=2907000 \mathrm{X} 1+3527000 \times 2+2485000 \times 3+$ $1834000 X 4$

(profit) (6)

Constraints (7)

$0.19 \mathrm{X} 1+0.16 \mathrm{X} 2+0.22 \mathrm{X} 3+0.29 \mathrm{X} 4<=288$

(koefisien)

$970 \mathrm{X} 1+1170 \mathrm{X} 2+834 \mathrm{X} 3+624 \mathrm{X} 4<=5000$

$485 \times 1<=387$

$585 \times 2<=486$

$417 \times 3<=586$

$312 \mathrm{X} 4<=418$

4. Formulation programming of linear programming scenario 4

Objective Fuction

$\mathrm{Z}=2907000 \mathrm{X} 1+3527000 \times 2+2485000 \times 3+$ $1834000 \mathrm{X} 4$

(profit) (6) 


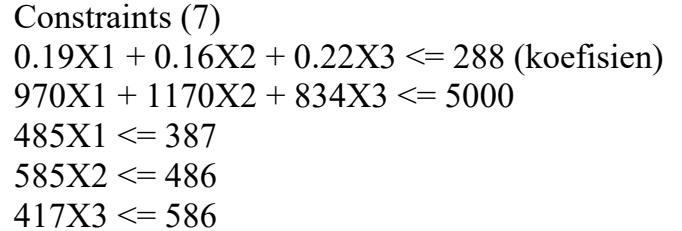

From scratch linear programming completed by method simplex in the system information planning, production and scheduling planting patterns obtained a result of each scenario shown in Table 2.

Table 2 Comparison every scenario

\begin{tabular}{|l|c|c|c|c|c|c|}
\hline \multirow{2}{*}{ SC } & Interval & \multicolumn{4}{|c|}{$\begin{array}{c}\text { Number of seeds grown } \\
\text { (mount) }\end{array}$} & \multirow{2}{*}{$\begin{array}{c}\text { Profit } \\
\text { (mp) }\end{array}$} \\
\cline { 3 - 6 } & (mount) & 1st & 2nd & 3rd & 4th & \\
\hline 1 & 1 & 774 & 531 & 164 & 115 & 5.327 .200 \\
\hline 2 & 2 & 774 & 531 & 487 & 357 & 6.426 .900 \\
\hline 3 & 3 & 774 & 972 & 1172 & 836 & 11.200 .000 \\
\hline 4 & 4 & 774 & 972 & 1172 & - & 8.742 .400 \\
\hline
\end{tabular}

Calculation scenarios 1, 2, 3, and 4 showed optimal results found in scenario 3 with a hose planting three months. In an analysis of solution optimal the number of planting in scenario 3 in proportion to the number of requests that is while in scenario 1 and 2 scenario the number of planting excess and also on scenario 4 the number of planting in 1 year only 3 cropping.

Results obtained in scenario 3 as much $\mathrm{Rp}$ 11.200.000,00 with the number of mushroom that must be produced in a period as many as $\mathrm{x} 1: 775, \mathrm{x} 2: 972, \mathrm{x} 3$ : 1172 and $x 4$ : 836, recommendations the number of mushrooms should be planted based on formulation programming linear and calculation with the methods simplex namely the results of multiplied by the number of seeds grown, planting patterns to be demonstrated in Table 3.

Table 3. Planting patterns distance planting three months

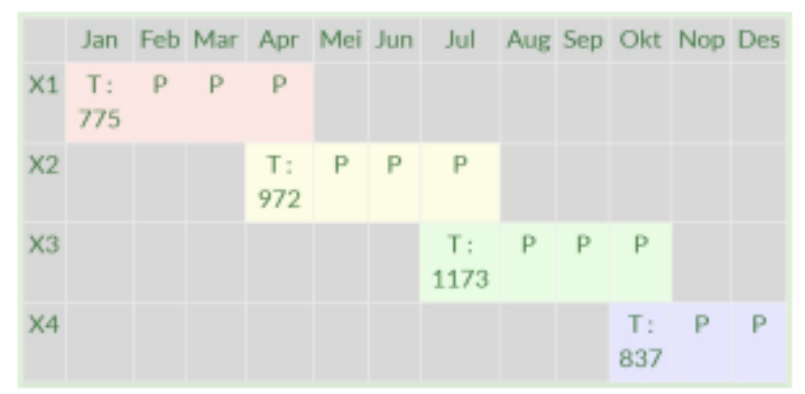

\section{Conclusion}

Production planning information system and scheduling of cropping patterns can provide recommendations for cropping patterns and the number of seeds that must be planted in one period. The amount of planting is adjusted to the number of existing requests that have been predicted using fuzzy time series, the results of four planting scenarios are obtained in the first scenario one month planting distance of Rp. 5,327,266.00, in the second scenario, the planting distance of two months is Rp. $6,426,950.00$, the value of the third scenario, the three-month planting distance with a value of $\mathrm{Rp}$ $11,200,000.00$, and a four-month planting distance with a value of $\mathrm{Rp} 8,742,400.00$ based on the results of scenarios one, two, three and four obtained the optimal value in the third scenario is Rp. $11,200,000.00$ by planting all onion seeds not all planted at the beginning, but breaking down with subsequent planting of red onion given a distance of three months as much as the first month planting 775 , second 972 , third 1172 , and fourth 836.

Advantages of agricultural products with the planting pattern of all seedlings planted at the beginning of Rp. $10,753,800.00$ while the profits achieved based on cropping patterns by laying out the number of seeds were given a three-month interval of Rp. 11,200,000.00, so that planting red onion seeds using a cropping pattern scheduling system increased profits by Rp. 446,800.00 per period.

\section{References}

1. S.A. Raza, F.C. Abdullakutty, S. Rathinam, Joint Determination of Process Mean, Price Differentiation, and Production Decisions with Demand Leakage: A Multi-Objective Approach. Applied Mathematical Modelling 40, 8446 -8463 (2016)

2. N.M.C. Garcia, A.G.B. Lozano, Y.A.R. Solis, A Crop Planning and Real-Time Irrigation Method Based on Site-Specific. Computers and Electronics in Agriculture 107, 20 - 28 (2015)

3. B.B. Pal, M. Kumar, S. Sen, A Priority based Interval-Valued Goal Programming Approach for Land Utilization. Second International conference on Computing, Communication and Networking Technologies (2010)

4. G. Dantzig, Linier Programming and Extensions. The Rand Corporation (1963)

5. A.G. Martín, C. Pozo, G.G. Gosalbez, Multistage Linear Programming Model for Optimizing Cropping Plan Decisions under the New Common Agricultural Policy. Land Use Policy 48, 515 - 524 (2015)

6. C.D. Rocco, R. Morabito, Production and Logistics Planning in the Tomato Processing Industry: A Conceptual Scheme and Mathematical Model. Computers and Electronics in Agriculture 127, 763 - 774 (2016)

7. Q. Song, B.S. Chissom, Forecasting Enrollments with Fuzzy Time Series Part 1. Fuzzy Sets and System 54, 1-9 (1993)

8. J.R. Munhoz, R. Morabito, Optimization Approache to Support Decision Making in the Production Planning of A Citrus Company: A Brazilian Case Study. Comput. Electron. Agric 107, 45-57 (2014)

9. J. Heizer, B. Render, Operation Management Tenth Edition. US: Pearson (2005)

10. N.A. Campbell, Biology Tenth Edition. US : Pearson (2002)

11. R.A.R Junqueira, R. Morabito, Production and Logistics Planning Considering Circulation Taxes 
in A Multi-Plant Seed Corn Company. Computers and Electronics in Agriculture 84, 100 - 110 (2012)

12. G.S. Permadi, A. Kusworo, R. Gernowo, Application Mail Tracking Using RSA Algorithm As Security Data and HOT-Fit a Model for Evaluation System, E3S Web of Conferences 31 (2018)

13. V. Democ, Z. Vyhnalikova, P. Alac, Proposal for Optimization of Information System. Procedia Economics and Finance 34, 477 - 484 (2015)

14. S.M. Chen, Forecasting Enrollments Based On Fuzzy Time Series. Information Sciences 327, 272 287 (1996) 